\title{
CORRIGENDUM $\mathscr{0}$
}

\author{
BRIAN J. SQUITIERI AND WiLliam A. GALlus JR. \\ Department of Geological and Atmospheric Sciences, Iowa State University, Ames, Iowa
}

(Manuscript received and in final form 5 February 2019)

\begin{abstract}
An error was discovered in the code used to calculate neighborhood equitable threat scores (nETSs) in Squitieri and Gallus. Replicating results with the error corrected revealed that most of the conclusions from Squitieri and Gallus remained the same, but with one significant new finding and one notable change in results. In the original manuscript, very few correlations between MCS QPF skill and LLJ forecast accuracy could be denoted among weakly forced cases, with none of them being statistically significant. Applying the aforementioned correction, it was found that QPF skill during the mature stage of MCSs significantly correlated with moisture forecast accuracy within developing LLJs for weakly forced events. It was also found that correlations between MCS QPF skill and LLJ potential temperature forecast accuracy occurred earlier in the evening.
\end{abstract}

Recently, it was discovered that a code used to calculate neighborhood-based equitable threat scores (nETSs) in Squitieri and Gallus (2016) had an error in it (introduced during code modification). After correcting the code, the results in Squitieri and Gallus (2016) were recomputed. Within the original manuscript, Figs. 4-7, 12, and 14-21 were all affected by the error. After the correction was applied, the conclusions of the paper remained roughly the same, with one significant new finding, and one noticeable change in results (addressed below, with an update to all other figures provided in the online supplemental material).

The significant new finding was that moisture forecast accuracy within developing LLJs significantly correlated with mature MCS QPF skill for weakly forced cases (Fig. 1, bottom row). It can be concluded that improvements in forecasting LLJ-bearing moisture during the early stages of LLJ evolution may improve QPFs when MCSs become mature. Previously, Squitieri and Gallus (2016) had found noticeable correlations of LLJ forecast accuracy with MCS QPF skill for weakly forced events to be rare, with little to no statistical significance noted (Fig. 1, top row). Because forecasting weakly forced convective phenomena remains a challenge for forecasters and model developers alike, this new correlation is important to note.

Regarding the other noticeable change in results, 0600-1200 UTC MCS QPF skill correlated more with 0600 and 0900 UTC LLJ potential temperature forecast accuracy for strongly forced cases before the correction. Now, MCS QPF skill at 0300-0900 and 0600-1200 UTC demonstrates more significant correlations with 0600 UTC LLJ potential temperature forecast accuracy (Fig. 2).

\section{REFERENCE}

Squitieri, B. J., and W. A. Gallus Jr., 2016: WRF forecasts of Great Plains nocturnal low-level jet driven MCSs. Part I: Correlation between low-level jet forecast accuracy and MCS precipitation forecast skill. Wea. Forecasting, 31, 1301-1323, https://doi.org/10.1175/WAF-D-15-0151.1.

Supplemental information related to this paper is available at the Journals Online website: https://doi.org/10.1175/WAF-D-19-0022.s1.

Corresponding author: Brian Squitieri, brianjs@iastate.edu 

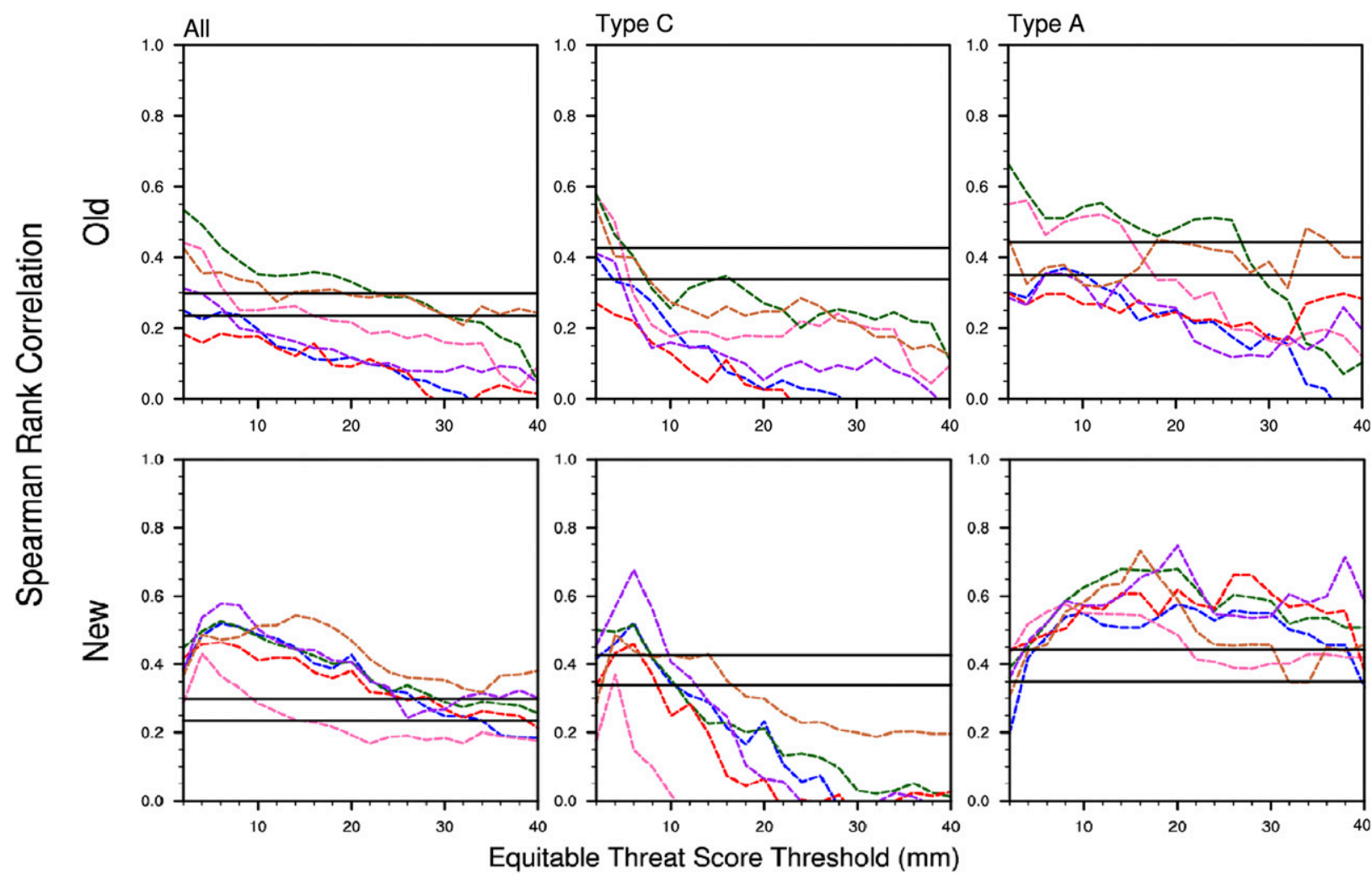

Equitable Threat Score Threshold $(\mathrm{mm})$

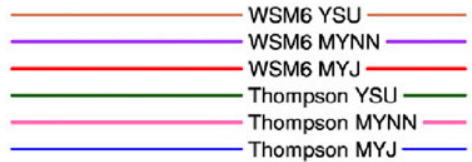

FIG. 1. As in Fig. 17 of Squitieri and Gallus (2016), but for Spearman rank correlations between the 6-h MCS QPF ETSs for 2-40-mm thresholds at 0600-1200 UTC and MAEs for the LLJ atmospheric water vapor content at 0300 UTC. (top) The older results before the corrections applied and (bottom) the newer results after the applied correction.
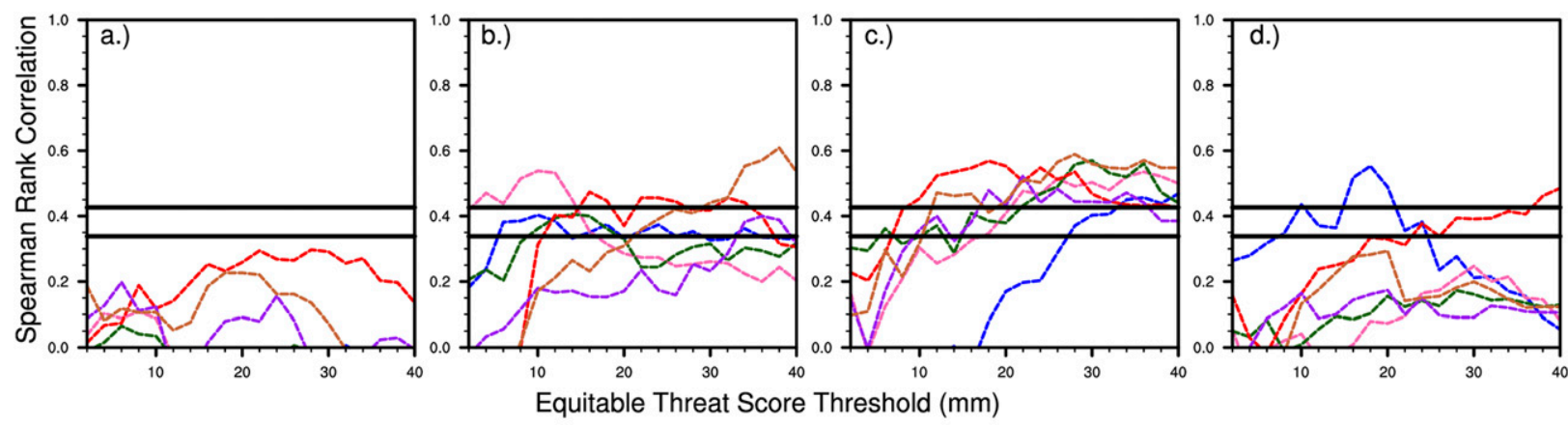

Equitable Threat Score Threshold $(\mathrm{mm})$

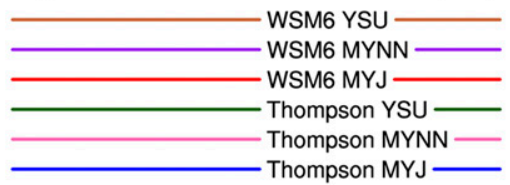

FIG. 2. As in Fig. 19 of Squitieri and Gallus (2016), for type C cases only, correlating (a) 0000-0600 UTC 6-h MCS QPF ETSs with 0300 UTC LLJ potential temperature MAEs, (b) 0300-0900 UTC 6-h MCS QPF ETSs with 0600 UTC LLJ potential temperature MAEs, (c) 0600-1200 UTC 6-h MCS QPF ETSs with 0600 UTC LLJ potential temperature MAEs, and (d) 0600-1200 UTC 6-h MCS QPF ETSs with 0900 UTC LLJ potential temperature MAEs. 